\title{
Outcomes of less invasive J-incision approach to aortic valve surgery
}

\author{
Douglas R. Johnston, MD, ${ }^{\text {a }}$ Fernando A. Atik, MD, ${ }^{a}$ Jeevanantham Rajeswaran, MSc, ${ }^{b}$ \\ Eugene H. Blackstone, MD, ${ }^{\mathrm{a}, \mathrm{b}}$ Edward R. Nowicki, MD, MS, ${ }^{\mathrm{a}}$ Joseph F. Sabik III, MD, ${ }^{\mathrm{a}}$ \\ Tomislav Mihaljevic, MD, ${ }^{a}$ A. Marc Gillinov, MD, ${ }^{a}$ Bruce W. Lytle, MD, ${ }^{a}$ and Lars G. Svensson, MD, PhD ${ }^{\mathrm{a}}$
}

Objective: Less invasive approaches to aortic valve surgery are increasingly used; however, few studies have investigated their impact on outcome. We sought to compare clinical outcomes after these approaches with full sternotomy using propensity-matching methods.

\begin{abstract}
Methods: From January 1995 to January 2004, a total of 2689 patients underwent isolated aortic valve surgery, 1193 via upper J-hemisternotomy and 1496 via full sternotomy. Because of important differences in patient characteristics between these groups, a propensity score based on 42 variables was used to obtain 832 well-matched patient pairs $(70 \%$ of possible cases).
\end{abstract}

Results: In-hospital mortality was identical for propensity-matched patients, $0.96 \%$ ( 8 in each). Occurrences of stroke $(P>.9)$, renal failure $(P=.8)$, and myocardial infarction $(P=.7)$ were similar. However, 24-hour mediastinal drainage was a third less after less invasive surgery (median, $250 \mathrm{vs} 350 \mathrm{~mL} ; P<.0001$ ), and fewer patients received transfusions $(24 \%$ vs $34 \% ; P<.0001)$. More patients undergoing less invasive surgery were extubated in the operating room $(12 \%$ vs $1.6 \% ; P<.0001)$, postoperative forced 1 -second expiratory volume was higher $(P=.009)$, and fewer had respiratory failure $(P=.01)$. Early after operation, pain scores were lower $(P<.0001)$ after less-invasive surgery and postoperative length of stay shorter $(P<.0001)$.

Conclusions: Within that portion of the spectrum of isolated aortic valve surgery where propensity matching was possible, minimally invasive aortic valve surgery had not only cosmetic advantages, but blood product use, respiratory, pain, and resource utilization advantages over full sternotomy, and no apparent detriments. Less invasive aortic valve surgery should be considered for most aortic valve operations. (J Thorac Cardiovasc Surg 2012;144:852-8)

Supplemental material is available online.

\section{Earn CME credits at}

http://cme.ctsnetjournals.org

From the Department of Thoracic and Cardiovascular Surgery, ${ }^{\mathrm{a}}$ Heart and Vascular Institute, and Department of Quantitative Health Sciences, ${ }^{\mathrm{b}}$ Research Institute, Cleveland Clinic, Cleveland, Ohio.

This study was supported in part by the Kenneth Gee and Paula Shaw, PhD, Chair in Heart Research (Dr Blackstone), the Donna and Ken Lewis Chair in Cardiothoracic Surgery and Peter Boyle Research Fund (Tomislav Mihaljevic), and the Judith Dion Pyle Chair in Heart Valve Research (Dr Gillinov).

Disclosures: Dr Mihaljevic is a consultant for Edwards Lifesciences and Intuitive Surgical and receives speaker fees from Intuitive Surgical. Dr Gillinov is a consultant to Edward Lifesciences and receives honoraria for speaking from St Jude Medical, Inc. He has an equity interest in Viacor, Inc.

Received for publication Sept 15, 2010; revisions received Nov 7, 2011; accepted for publication Dec 6, 2011; available ahead of print Jan 13, 2012.

Address for reprints: Lars G. Svensson, MD, PhD, Department of Thoracic and Cardiovascular Surgery, Cleveland Clinic, 9500 Euclid Ave/Mail Stop J4-1, Cleveland, OH 44195 (E-mail: svennsl@ccf.org).

$0022-5223 / \$ 36.00$

Copyright $\odot 2012$ Published by Elsevier Inc. on behalf of The American Association for Thoracic Surgery

doi:10.1016/j.jtcvs.2011.12.008
In the mid-1990s, less invasive "keyhole" approaches for valve operations were pioneered with the intent of reducing morbidity, postoperative pain, and blood loss, improving cosmesis, shortening hospital stay, and reducing cost compared with the 50-year-old full sternotomy approach. ${ }^{1-10}$ Furthermore, it was believed that less spreading of the incision, not interfering with the diaphragm, and less tissue dissection might improve outcomes, particularly respiratory function. ${ }^{7,8}$ Although clinical studies suggest that some of these benefits have been realized, there has been no confirmatory large study or randomized trial. ${ }^{1-10}$ Because patients undergoing aortic valve surgery are in general older and sicker than those undergoing isolated mitral valve surgery, cosmetic benefits of less invasive aortic valve surgery may not be as important. Yet potential improvement in postoperative pain and respiratory function, particularly in patients with advanced respiratory disease, and reduced blood loss, transfusion requirement, and intensive care unit (ICU) and hospital lengths of stay are of even greater possible benefit in this older population with more severe comorbidities. Despite these perceived advantages of less invasive surgery, full sternotomy remains the most widely used approach in isolated aortic valve surgery. Therefore, to evaluate the potential benefits of a minimally invasive approach, we performed a propensitymatched comparison of short- and long-term outcomes in 


\section{Abbreviations and Acronyms \\ $\mathrm{CL}=$ confidence limits \\ $\mathrm{FEV}_{1}=$ forced expiratory volume in 1 second \\ ICU $=$ intensive care unit}

patients who underwent less invasive aortic valve surgery compared with patients who had full sternotomy.

\section{PATIENTS AND METHODS Patients}

From January 1995 to January 2004, a total of 2689 patients underwent primary isolated aortic valve repair $(n=438)$ or replacement $(n=2251)$ surgery with $(n=25)$ or without $(n=2664)$ tricuspid valve repair; patients undergoing concomitant mitral valve surgery or coronary artery bypass grafting were excluded, as were those with active endocarditis. A minimally invasive approach was intended in 1193 (44\%) patients and full sternotomy in $1496(56 \%)$. In more recent years, the proportion of aortic valve operations performed through a less invasive incision has risen to $60 \%$ to $65 \%$ (Figure E1). Mean age was 60 \pm 6 years (range, $18-97$ years), and $66 \%$ were men.

Data were in part retrieved from the prospective Cardiovascular Information Registry and in part from each patient's medical record. These data were approved for use in research by the institutional review board, with patient consent waived.

\section{Surgical Technique}

Conventional general anesthesia was used in all patients regardless of surgical approach, with identical protocols. Patients who underwent less invasive surgery had an 8 - to 10 -cm skin incision. ${ }^{1,3,7}$ The upper sternum was divided in the midline, and this sternotomy was extended into the right fourth intercostal space, forming a J. ${ }^{7-9}$ Approach to the aortic valve was via either an oblique aortotomy carried into the noncoronary cusp or a transverse aortotomy above the sinotubular junction, at the discretion of the surgeon. Aortic valve repair or replacement was then carried out according to the surgeon's standard technique.

Vacuum-assisted cardiopulmonary bypass with central cannulation was used in all patients. ${ }^{11}$ Intraoperative transfusions, anesthetic technique, and timing of extubation were at the anesthesiologists' discretion. Intraoperative and postoperative transfusion and extubation were not driven by rigorous protocols, except that the philosophy of the teams was to minimize use of homologous blood products.

\section{Study Design}

A number of differences in patient characteristics between less invasive and full sternotomy groups precluded interpretation of direct comparisons of outcomes (Table 1). Therefore, to reduce influence of selection, we used propensity matching to approximate a randomized trial. ${ }^{12-14}$ In the spirit of such a trial, we followed the "intent-to-treat" principle, such that the 34 $(2.8 \%)$ patients with an intended less invasive approach who were converted to full sternotomy were retained in the less invasive group. Initially, a parsimonious model based on variables in Appendix 1 was formulated by logistic regression analysis using bagging ${ }^{15}$ (Table E1) to understand the drivers of patient selection. To this model were added nonsignificant variables to form a semisaturated propensity model. From this logistic regression model $(\mathrm{C}=.77)$ based on 42 preoperative and procedure variables predictable preoperatively (Appendix 1), a propensity score was generated for each patient. Greedy matching based on the propensity score was used to identify 832 patient pairs for comparison, $70 \%$ of all possible pairs (Table E2) ${ }^{16}$ Figure E2 indicates the portion of the spectrum of propensity from which matched pairs were obtained, and Table E2 documents characteristics of patients for whom either less invasive or full sternotomies were more heterogeneously applied during the study period. Figure E3 shows standardized differences ${ }^{17}$ for a number of variables before and after matching, illustrating success in formulating comparable groups. This strategy was repeated for the 2000-2004 cohort ( $\mathrm{n}=648$, less invasive patients; $\mathrm{n}=712$, full sternotomy patients) for whom incentive spirometry and pain scores were available, yielding 440 propensity-matched patient pairs, $68 \%$ of all possible pairs.

\section{Outcomes}

Outcomes assessed included intraoperative support (myocardial ischemic time, cardiopulmonary bypass time), postoperative in-hospital mortality and morbidity (defined in accordance with the Society of Thoracic Surgeons National Database: http://www.ctsnet.org/file/rptData Specifications252_1_ForVendorsPGS.pdf), blood product use, mediastinal drainage at 6 and 24 hours, hematocrit at hospital discharge, time to extubation (which was at the discretion of attending anesthesiologists in either the operating room or ICU), all incentive spirometry values after extubation, all pain scores, length of ICU and hospital stay, and long-term survival.

Incentive spirometry and pain scoring were performed and recorded prospectively and consecutively from January 2000 to January 2004. During that time 880 matched and 480 unmatched patients $(n=1260 ; 47 \%$ of study group) underwent operation. Both spirometry and pain scores were obtained routinely as part of clinical care after surgery. Spirometry was performed periodically by respiratory therapists using a Renaissance II bedside spirometer (Puritan Bennett, Carlsbad, Calif) until hospital discharge; a total of 3030 values were available for 621 matched patients $(71 \%)$. Forced expiratory volume in 1 second $\left(\mathrm{FEV}_{1}\right)$ values measured by this equipment were normalized to percent of predicted by the NHANES algorithm and used for analysis. ${ }^{18}$ From patients' arrival in the ICU to hospital discharge, nursing staff recorded pain intensity-ranging from 0 (none) to 10 (severe) - approximately every 4 hours using the extensively validated Wong-Baker FACES (Facial Expression Scale) pain assessment. ${ }^{19,20}$ A total of 21,154 valid pain scores were available for 718 matched patients $(82 \%)$.

Survival was assessed by follow-up every 2 years using a questionnaire approved by the institutional review board, supplemented by data from the Social Security Death Master File. ${ }^{21,22}$ A total of 10,893 patient-years of information was available for analyses among matched patients, with mean follow-up of $6.5 \pm 3.0$ years; $25 \%$ of survivors were followed up more than 9.1 years and $10 \%$ more than 10 years. For matched patients undergoing less invasive surgery, 5641 patient-years of follow-up were available for analyses, mean follow-up was $6.8 \pm 2.9$ years, and $10 \%$ were followed up more than 10 years. For matched patients undergoing full sternotomy, 5252 patient-years of follow-up were available for analyses, mean follow-up was $6.3 \pm 3.0$ years, and $10 \%$ were followed up more than 10 years.

\section{Comparisons}

Categorical outcomes were compared using either the $\chi^{2}$ or Fisher's exact test and continuous outcomes by the Wilcoxon rank sum nonparametric test. To compare temporal pattern of postoperative $\mathrm{FEV}_{1}$ across time, we analyzed all 3030 repeated continuous values longitudinally using mixed-model regression, ${ }^{16}$ with autoregressive order 1 correlation structure to accommodate the correlated nature of the observations within each patient.

To compare temporal pattern of postoperative pain across time, we combined pain scores into 5 categories because of low frequency of higher pain scores: 0 (pain score 0), 1 (pain scores 1-3), 2 (pain scores 4-6), 3 (pain scores 7 and 8), and 4 (pain scores 9 and 10). All 21,154 pain score categories were then analyzed longitudinally using a nonlinear cumulative logit mixed model for repeated measures that resolved a number of temporal 
TABLE 1. Patient characteristics and operative details by surgical approach: Overall unmatched

\begin{tabular}{|c|c|c|c|c|c|}
\hline \multirow[b]{2}{*}{ Variable } & \multicolumn{2}{|c|}{ Less invasive $(n=1193)$} & \multicolumn{2}{|c|}{ Full sternotomy $(n=1496)$} & \multirow[b]{2}{*}{$\boldsymbol{P}$} \\
\hline & No. & $\%$ & No. & $\%$ & \\
\hline \multicolumn{6}{|l|}{ Demography } \\
\hline Women & 390 & 33 & 532 & 36 & .12 \\
\hline Age $(y)$, mean \pm SD & \multicolumn{2}{|c|}{$59 \pm 16$} & \multicolumn{2}{|c|}{$61 \pm 16$} & .01 \\
\hline $\mathrm{BMI}\left(\mathrm{kg} \cdot \mathrm{m}^{-2}\right)$, mean $\pm \mathrm{SD}$ & \multicolumn{2}{|c|}{$28 \pm 5.6$} & \multicolumn{2}{|c|}{$28 \pm 5.8$} & .005 \\
\hline NYHA functional class & & & & & $<.0001$ \\
\hline I & 282 & 24 & 360 & 24 & \\
\hline II & 719 & 60 & 775 & 52 & \\
\hline III & 154 & 13 & 268 & 18 & \\
\hline IV & 38 & 3.2 & 93 & 6.2 & \\
\hline \multicolumn{6}{|l|}{ Indication for operation } \\
\hline Degenerative & 927 & 78 & 818 & 55 & $<.0001$ \\
\hline Rheumatic & 105 & 8.8 & 112 & 7.5 & .2 \\
\hline Congenital & 69 & 5.8 & 115 & 7.7 & .05 \\
\hline Other & 92 & 7.7 & 451 & 30 & $<.0001$ \\
\hline \multicolumn{6}{|l|}{ Cardiac comorbidity } \\
\hline LV dysfunction & $198 / 1156^{*}$ & 17 & $327 / 1375^{*}$ & 24 & $<.0001$ \\
\hline Tricuspid regurgitation $>$ moderate & $14 / 1113^{*}$ & 1.3 & $57 / 1211^{*}$ & 47 & $<.0001$ \\
\hline Atrial fibrillation/flutter & 36 & 3 & 74 & 4.9 & .01 \\
\hline \multicolumn{6}{|l|}{ Noncardiac comorbidity } \\
\hline Hypertension & $601 / 1172^{*}$ & 51 & $869 / 1459 *$ & 60 & $<.0001$ \\
\hline Treated diabetes & $68 / 1170^{*}$ & 5.8 & $133 / 1436$ & 9.3 & .001 \\
\hline COPD & $177 / 1101^{*}$ & 16 & $282 / 1185$ & 24 & $<.0001$ \\
\hline \multicolumn{6}{|l|}{ Procedure } \\
\hline Aortic valve repair & 194 & 16 & 244 & 16 & $>.9$ \\
\hline Aortic valve replacement & 999 & 84 & 1252 & 84 & $>.9$ \\
\hline \multicolumn{6}{|l|}{ Label size $(\mathrm{mm}) \dagger$} \\
\hline$\leq 19$ & 97 & 9.7 & 131 & 11 & \\
\hline $20 / 21$ & 314 & 31 & 331 & 27 & \\
\hline $22 / 23$ & 366 & 37 & 399 & 33 & \\
\hline $24 / 25$ & 170 & 17 & 228 & 19 & \\
\hline $26 / 27$ & 49 & 4.9 & 105 & 8.6 & \\
\hline$\geq 28$ & 3 & 0.3 & 32 & 2.6 & \\
\hline Tricuspid valve repair & 3 & 0.25 & 23 & 1.5 & .0007 \\
\hline
\end{tabular}

$S D$, Standard deviation; $B M I$, body mass index; $N Y H A$, New York Heart Association; $L V$, left ventricular; $C O P D$, chronic obstructive pulmonary disease. *Number of patients with data available. $\dagger 1226$ (out of 1252) patients in the full sternotomy group have label size data.

components and their shaping parameters. ${ }^{23}$ Each component was independently modulated by a time function with common random intercept.

Survival was compared nonparametrically by the Kaplan-Meier method and parametrically by a temporal decomposition model. ${ }^{23}$

\section{Presentation}

Categorical variables are summarized as frequencies and percentages and continuous variables as means \pm standard deviations, or as equivalent 15th, 50th (median), and 85th percentiles (for consistency with \pm 1 standard deviation) when data were skewed. Asymmetric $68 \%$ confidence limits $(\mathrm{CL})$ are consistent with \pm 1 standard error. All analyses were performed using SAS (SAS Institute, Inc, Cary, NC) statistical software version 9.1 .

\section{RESULTS}

\section{Success of Intended Approach}

Of the 34 conversions from a less invasive approach to full sternotomy, 18 (53\%) occurred before the aortic clamp was applied, mostly because heart position precluded adequate exposure; $3(8.8 \%)$ occurred while the clamp was in place, primarily because of unusual anatomy; 12 $(35 \%)$ occurred after clamp removal, primarily for repair of coronary sinus injury from the retrograde cardioplegia catheter, but also for left heart distention and ventricular fibrillation; 1 had insufficient documentation to classify (Table E3).

Among propensity-matched patients, ischemic time was shorter after a less invasive approach than after full sternotomy (58 \pm 24 vs $71 \pm 28$ minutes; $P<.0001)$ as was cardiopulmonary bypass time (73 \pm 32 vs $95 \pm 37$ minutes; $P<.0001)$.

\section{In-Hospital Mortality and Morbidity}

In-hospital mortality was identical, $0.96 \%$ (CL, $0.63 \%$ $1.3 \%)$, among matched patients $(P>.9$, Table 2$)$. Postoperative respiratory insufficiency (prolonged ventilatory support 
TABLE 2. In-hospital outcomes by surgical approach, overall and in propensity-matched patients*

\begin{tabular}{|c|c|c|c|c|c|c|c|c|c|c|}
\hline \multirow[b]{3}{*}{ Outcome } & \multicolumn{5}{|c|}{ Overall } & \multicolumn{5}{|c|}{ Propensity matched } \\
\hline & \multicolumn{2}{|c|}{$\begin{array}{l}\text { Less invasive } \\
(\mathrm{n}=1193)\end{array}$} & \multicolumn{2}{|c|}{$\begin{array}{l}\text { Full sternotomy } \\
\quad(n=1496)\end{array}$} & \multirow[b]{2}{*}{$\boldsymbol{P}$} & \multicolumn{2}{|c|}{$\begin{array}{l}\text { Less invasive } \\
\quad(\mathbf{n}=\mathbf{8 3 2})\end{array}$} & \multicolumn{2}{|c|}{$\begin{array}{l}\text { Full sternotomy } \\
\quad(\mathbf{n}=\mathbf{8 3 2})\end{array}$} & \multirow[b]{2}{*}{$\boldsymbol{P}$} \\
\hline & $\mathbf{n}$ & $\%$ & $\mathbf{n}$ & $\%$ & & $\mathbf{n}$ & $\%$ & $\mathbf{n}$ & $\%$ & \\
\hline Death & 10 & 0.84 & 30 & 2.0 & .01 & 8 & 0.96 & 8 & 0.96 & $>.9$ \\
\hline Stroke & 15 & 1.3 & 32 & 2.1 & .08 & 11 & 1.3 & 11 & 1.3 & $>.9$ \\
\hline Renal failure & 7 & 0.59 & 25 & 1.7 & .01 & 6 & 0.72 & 7 & 0.84 & .8 \\
\hline Myocardial infarction & 5 & 0.42 & 4 & 0.27 & .5 & 4 & 0.48 & 3 & 0.36 & .7 \\
\hline Deep sternal wound infection & 9 & 0.75 & 12 & 0.8 & .9 & 5 & 0.601 & 7 & 0.84 & .6 \\
\hline Sepsis/septicemia & 14 & 1.2 & 37 & 2.5 & .01 & 11 & 1.3 & 18 & 2.2 & .2 \\
\hline Return to OR for bleeding & 60 & 5.0 & 77 & 5.1 & .9 & 46 & 5.5 & 36 & 4.3 & .3 \\
\hline $\mathrm{RBC}$ transfusion & 267 & 22 & 614 & 41 & $<.0001$ & 202 & 24 & 286 & 34 & $<.0001$ \\
\hline Respiratory insufficiency & 31 & 2.6 & 107 & 7.2 & $<.0001$ & 24 & 2.9 & 45 & 5.4 & .01 \\
\hline
\end{tabular}

$O R$, Operating room; $R B C$, red blood cell. *Morbidities as defined by, and submitted to, the Society of Thoracic Surgeons Adult Cardiac National Database.

beyond 24 hours) occurred less frequently after less invasive surgery than after full sternotomy; all other in-hospital complications occurred with similar frequency (Table 2).

\section{Bleeding and Transfusion}

Prevalence of return to the operating room for bleeding was similar in matched groups (Table 2); however, mediastinal drainage was a third less at 6 and 24 hours after a less invasive approach (15th/50th/85th percentiles, 50/100/250 $\mathrm{mL}$ and $150 / 250 / 400 \mathrm{~mL}$, respectively) than after full sternotomy $(100 / 150 / 300 \mathrm{~mL}$ and $250 / 350 / 700 \mathrm{~mL}$, respectively); $P<.0001$. Transfusion was less frequent after less invasive surgery than after full sternotomy $(24 \%$ vs $34 \%$; $P<.0001$; Table 2), and despite this, hematocrit value at discharge was similar between groups $(32 \% \pm 4.2 \%$ for less invasive surgery vs $32 \% \pm 3.7 \%$ for full sternotomy; $P=.6)$.

\section{Respiratory Function}

A substantially higher proportion of matched patients were extubated in the operating room after less invasive surgery than after full sternotomy $(12 \%$ vs $1.6 \% ; P<.0001)$. Median time to extubation was also shorter (5.2 hours [CL, 2.5-12 hours] vs 6.9 hours [CL, 3.6-21 hours]; $P<.0001$ ). $\mathrm{FEV}_{1}$ was higher immediately after extubation in the less invasive group, with the difference narrowing during the first 36 hours after surgery (Figure 1).

\section{Postoperative Pain}

The general temporal pattern of pain score categories is illustrated in Figure 2, A. During the first 24 postoperative hours, only about a third of patients were pain free, and this proportion rose to about $60 \%$ by day 3 and stabilized. Matched patients undergoing less invasive surgery had less pain throughout their postoperative course than those undergoing full sternotomy $(P<.0001$; Figure $2, B)$.

\section{Length of Stay}

Among matched patients, median ICU and postoperative lengths of stay were shorter in the less invasive group than in the full sternotomy group. ICU stay (15th percentile/median/85th percentile) was $1 / 1 / 2$ versus $1 / 1 / 3$ days $(P<.0001)$. Total postoperative length of stay was $4 / 6 / 9.2$ versus $5 / 6 / 12$ days $(P<.0001)$.

\section{Survival}

Survival at 1,5 , and 10 years was $96 \%, 90 \%$, and $77 \%$ after less invasive surgery and $95 \%, 86 \%$, and $73 \%$ after full sternotomy among matched patients $(P=.2$, Figure 3$)$.

\section{DISCUSSION}

Patients are increasingly self-educated and aware of minimally invasive options for cardiac surgery. In some cases,

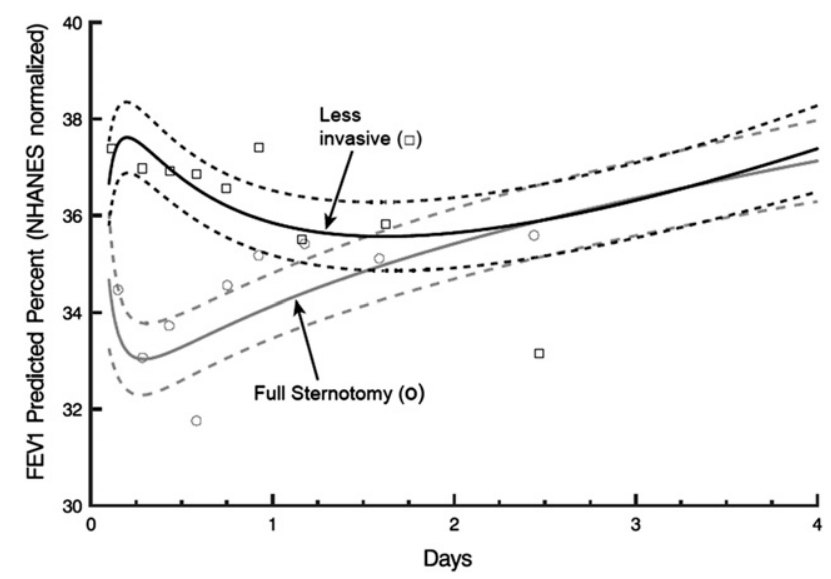

FIGURE 1. Temporal pattern of postextubation forced 1-second expiratory volume $\left(\mathrm{FEV}_{1}\right)$ as percent of predicted after less invasive and full sternotomy aortic valve surgery among propensity-matched patients. Solid lines are parametric estimates of temporal trend enclosed within dashed lines $68 \%$ confidence limits (equivalent to \pm 1 standard error). Symbols represent data grouped within time frames without regard for repeated assessment, simply to provide crude verification of model fit. 

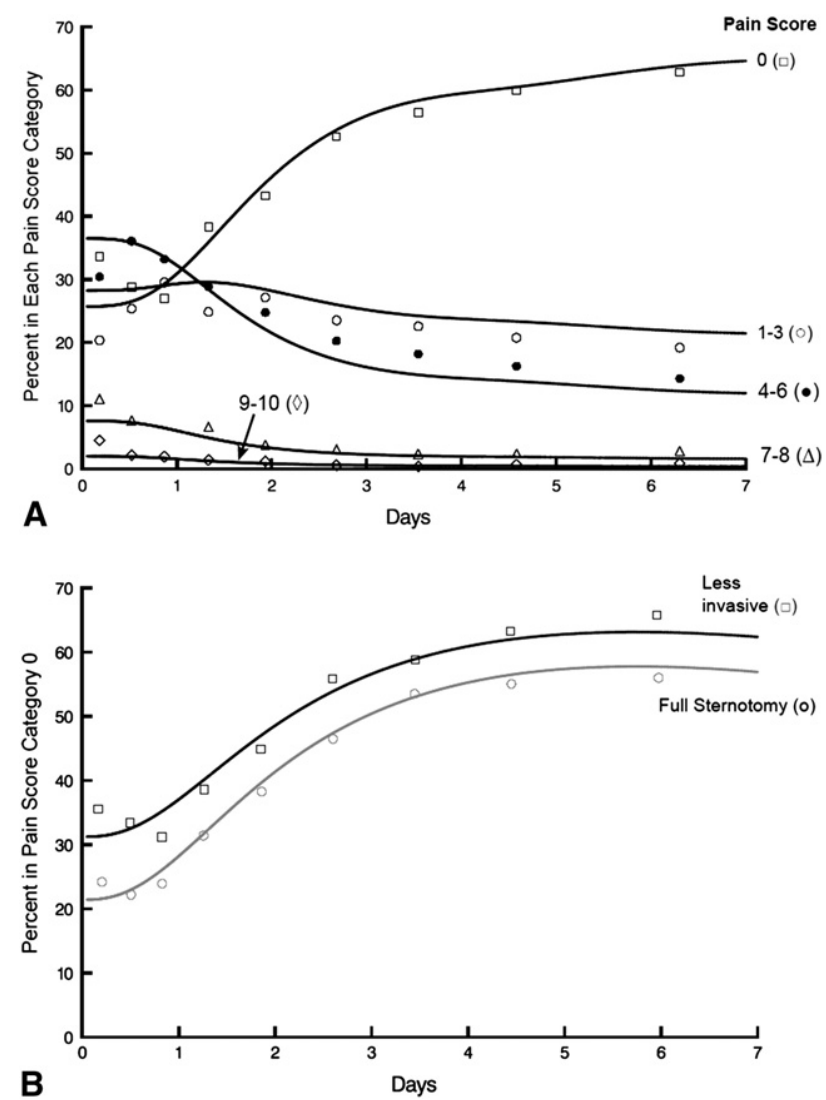

FIGURE 2. Temporal pattern of pain score categories after less invasive versus full sternotomy aortic valve surgery among propensity-matched patients. Symbols represent data grouped within time frames without regard for repeated assessment, simply to provide crude verification of model fit. Solid lines are parametric estimates of percentage of patients in each category. A, All pain score categories. B, Proportion of patients without pain (category 0$)$.

they are being referred or self-refer for surgery only if a less invasive procedure can be performed. Concerns have been raised that less invasive procedures may result in longer operative, bypass, and aortic clamp times, increasing risk of complications. Were this the case, the perceived benefits of improved cosmesis and less pain and bleeding might not be worth the increased risk. Some patients with aortic valve disease also have not been offered less invasive approaches because of perceived fragility or advanced age. Indeed, on the basis of our experience, we find it particularly advantageous to use a less invasive approach for elderly frail patients and those with advanced respiratory disease. Of note, risk of respiratory insufficiency was lower in this study with the J-incision, and $\mathrm{FEV}_{1}$ was higher early postoperatively. Risk of wound infection and sepsis may also be lower and easier to deal with.

As innovative transcatheter approaches to aortic valve insertion are being developed and tested in clinical trials ${ }^{24}$ and used in practice, the results of full sternotomy versus less invasive surgery deserve close attention by cardiac surgeons,

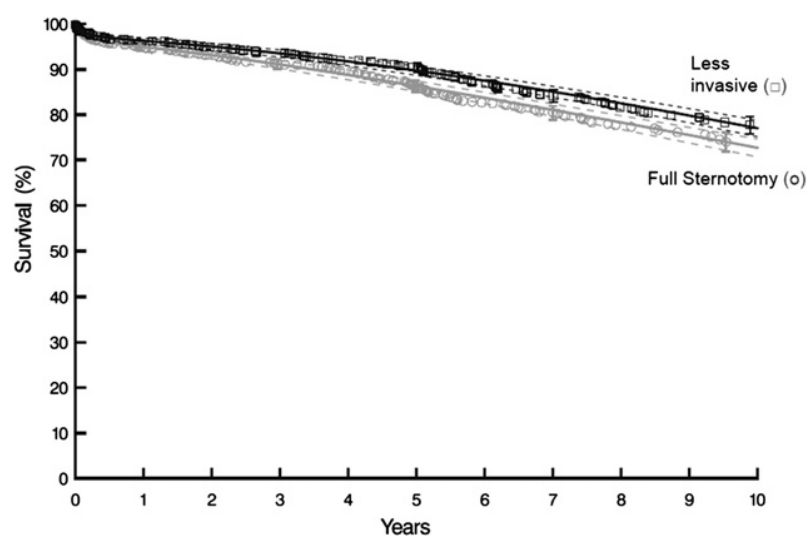

FIGURE 3. Survival after less invasive and full sternotomy aortic valve surgery among propensity-matched patients. Each symbol represents a death, positioned actuarially, vertical bars $68 \%$ confidence limits, and numbers in parentheses patients remaining at risk. Solid lines are parametric estimates enclosed within dashed $68 \%$ confidence limits (equivalent to \pm 1 standard error).

who may be able to offer a safer and less traumatic alternative. Specifically, the "gold standard" of aortic valve surgery via a full sternotomy may not be as tenable, as operative technique, anesthesia, perfusion, and postoperative care have improved, particularly for high-risk patients. Outcomes and potential advantages of currently available techniques for aortic valve surgery must be well understood to accurately evaluate transcatheter approaches for any given patient.

\section{Principal Findings}

In less than $3 \%$ of cases, a less invasive incision had to be converted to full sternotomy. That the majority of conversions to full sternotomy occurred before aortic clamping suggests that a careful evaluation of adequacy of exposure of the aorta and right atrium is necessary to achieve optimal results. Computed tomography scanning before surgery in borderline cases, particularly if an ascending aortic replacement is contemplated, may be of value.

A smaller number of cases were converted when a change in planned procedure occurred based on new information obtained in the operating room. Examples included detecting systolic anterior motion of the mitral valve requiring concomitant myectomy. Coronary sinus perforation and right atrial bleeding accounted for several conversions, suggesting that particular care is required in placing the retrograde cardioplegia catheter and venous cannulas because palpation cannot be used to check positioning. Indeed, some of us have abandoned using retrograde cardioplegia for minimally invasive J-incisions. In addition, access for deairing is limited. A maneuver that facilitates deairing is to slide a malleable retractor down to the left ventricle and compress it. Carbon dioxide field flooding is used routinely because of the 25-times quicker rate of absorption of 
carbon dioxide compared with air. Venting the left ventricle is also limited with this approach, resulting in 4 conversions to place a vent or to adequately defibrillate. We routinely apply adhesive transcutaneous defibrillator pads before the operation to facilitate rapid defibrillation.

This study shows no disadvantages of less invasive surgery and several advantages: (1) postoperative pain is less, (2) blood loss and blood use are lower, (3) time to extubation is shorter and early respiratory capacity improved, and (4) length of stay is shorter. Although there was no major difference in survival, it should be noted that hospital and 30-day survivals were above $99 \%$ in both groups, and thus to show a difference would be statistically difficult. Of note, early and late survivals were not compromised.

Less perioperative bleeding and fewer blood transfusions are likely due to the smaller mediastinal dissection required for the less invasive approach. Less pain is likely related to less surgical dissection, less spreading of the sternum, and no escalation of tension on the posterior rib head and costovertebral ligaments because the chest wall is not opened like a trap door. The better pulmonary function can be explained by no interference with the diaphragm or dissection along it. Also, with less chest wall pain, patients may have less splinting of the chest and thus can breathe more deeply. All of these factors likely combine to influence length of stay. In an era in which health care costs are increasingly scrutinized and efficiency has become a paramount concern, the difference in length of stay has significant implications in terms of bed occupancy and hospital cost.

\section{Implications for Transcatheter Aortic Valve Replacement}

Transcatheter aortic valve technology has progressed from an area of intense engineering interest to a clinical reality. One device is currently in clinical trials in the United States, and several are used extensively in Europe. ${ }^{24} \mathrm{Al}$ though there is considerable excitement regarding the potential of transcatheter aortic valve replacement, the appropriate patient in whom to apply this technology remains uncertain. A number of recent reports have questioned the use of available risk-scoring tools to evaluate patients for transcatheter aortic valve replacement ${ }^{25}$ because observed mortality is often much lower than would be expected based on the score. In a large real-world patient cohort, we show that less than $1 \% 30$-day mortality and $1.3 \%$ risk of stroke can be achieved. These results should serve as a benchmark for comparison with results of transcatheter aortic valve replacement in patients who are also considered for surgical aortic valve replacement. Furthermore, when examining patients by age at operation at our institution, ${ }^{26}$ for the 720 undergoing primary aortic valve replacement who were less than 70 years old, risk of death from January 2001 to January 2008 was $0.28 \%$. It was only for patients older than 80 years undergoing reoperation that the risk increased above that of reoperation in patients less than 70 years of age $(2.3 \%)$, to $5.6 \% .^{26}$

\section{Limitations}

Although heterogeneity in use of less invasive aortic valve surgery provided the opportunity for comparisons with full sternotomy, clearly, as a group, patients undergoing full sternotomy were sicker, with a less favorable prognosis than those undergoing less invasive surgery. When a propensity score was used to match patients, the comparison groups were intermediate in risk (Figure E2), and differences in most outcomes appeared to be explained by differences in patient characteristics rather than surgical approach (Table E2). Indeed, like randomized trials that address only that portion of the spectrum of disease for which equipoise is present, propensity methods address only that portion of the spectrum for which heterogeneity in practice is discovered (virtual equipoise). In both cases, it is tempting to extrapolate beyond the confines of the overlapping portions of the spectrum; we caution the reader to understand that at both extremes of the spectrum, surgeons at Cleveland Clinic during the period of this study systematically performed either less invasive or full sternotomy operations, and the factors driving this decision are those identified in Table 1: obesity, left ventricular function, acuity, disease etiology, tricuspid valve regurgitation, era of surgery, and intent to repair rather than replace the valve. We acknowledge that selection bias cannot be completely reversed by propensity-based methods and, in this study, cannot completely overcome distinct surgeon preferences. Because treatment was not masked, patients' selfreporting of pain scores may have been biased as well. This is also a single-institution study, which limits its generalizability. Nevertheless, time to extubation, spirometry values, and pain scores would largely have been uninfluenced by potential surgeon biases because these were determined or routinely collected by respiratory therapists, anesthesiologists, or nurses.

\section{CONCLUSIONS}

Less invasive aortic valve surgery has cosmetic, blood product use, respiratory, and pain advantages and is equal in safety to full sternotomy. In addition, it appears to result in shorter length of stay, with potential cost savings. We routinely use the approach for most aortic valve and ascending aortic procedures, excluding those requiring additional procedures such as coronary artery or mitral valve surgery.

\section{References}

1. Cosgrove DM III, Sabik JF, Navia JL. Minimally invasive valve operations. Ann Thorac Surg. 1998;65:1535-8; discussion 1538-9.

2. Gundry SR, Shattuck OH, Razzouk AJ, del Rio MJ, Sardari FF, Bailey LL. Facile minimally invasive cardiac surgery via ministernotomy. Ann Thorac Surg. 1998 65:1100-4. 
3. Cohn LH, Adams DH, Couper GS, Bichell DP, Rosborough DM, Sears SP, et al. Minimally invasive cardiac valve surgery improves patient satisfaction while reducing costs of cardiac valve replacement and repair. Ann Surg. 1997;226:421-6; discussion 427-8.

4. Chitwood WR Jr, Wixon CL, Elbeery JR, Moran JF, Chapman WH, Lust RM. Video-assisted minimally invasive mitral valve surgery. $J$ Thorac Cardiovasc Surg. 1997;114:773-80; discussion 780-2.

5. Schroeyers P, Wellens F, De Geest R, Degrieck I, Van Praet F, Vermeulen Y, et al. Minimally invasive video-assisted mitral valve surgery: our lessons after a 4-year experience. Ann Thorac Surg. 2001;72:S1050-4.

6. Grossi EA, Galloway AC, LaPietra A, Ribakove GH, Ursomanno P, Delianides J, et al. Minimally invasive mitral valve surgery: a 6-year experience with 714 patients. Ann Thorac Surg. 2002;74:660-3; discussion 3-4.

7. Svensson LG. Minimal-access "J" or "j" sternotomy for valvular, aortic, and coronary operations or reoperations. Ann Thorac Surg. 1997;64:1501-3.

8. Svensson LG, D'Agostino RS. Minimal-access aortic and valvular operations, including the "J/j" incision. Ann Thorac Surg. 1998;66:431-5.

9. Svensson LG, D'Agostino RS. "J" incision minimal-access valve operations. Ann Thorac Surg. 1998;66:1110-2.

10. Svensson LG, Nadolny EM, Kimmel WA. Minimal access aortic surgery including re-operations. Eur J Cardiothorac Surg. 2001;19:30-3

11. Banbury MK, White JA, Blackstone EH, Cosgrove DM 3rd. Vacuum-assisted venous return reduces blood usage. J Thorac Cardiovasc Surg. 2003;126:680-7.

12. Rosenbaum PR, Rubin DB. The central role of the propensity score in observational studies for causal effects. Biometrika. 1983;70:41-55.

13. Rubin DB. The design versus the analysis of observational studies for causal effects: parallels with the design of randomized trials. Stat Med. 2007;26:20-36.

14. Blackstone EH. Comparing apples and oranges. J Thorac Cardiovasc Surg. 2002; 123:8-15.

15. Breiman L. Bagging predictors. Machine Learning. 1996;24:123-40.
16. Bergstralh EJ, Konsanke JL. Computerized matching of cases to controls. Technical report No. 56. Department of Health Science Research. Rochester (MN): Mayo Clinic; 1995.

17. D'Agostino RB Jr. Propensity score methods for bias reduction in the comparison of a treatment to a non-randomized control group. Stat Med. 1998;17:2265-81.

18. Mannino DM, Buist AS, Petty TL, Enright PL, Redd SC. Lung function and mortality in the United States: data from the First National Health and Nutrition Examination Survey follow up study. Thorax. 2003;58:388-93.

19. Wong DL, Baker CM. Pain in children: comparison of assessment scales. Pediatr Nurs. 1988;14:9-17.

20. Bieri D, Reeve RA, Champion GD, Addicoat L, Ziegler JB. The Faces Pain Scale for the self-assessment of the severity of pain experienced by children: development, initial validation, and preliminary investigation for ratio scale properties. Pain. 1990;41:139-50.

21. Boyle CA, Decoufle P. National sources of vital status information: extent of coverage and possible selectivity in reporting. Am J Epidemiol. 1990;131:160-8.

22. Newman TB, Brown AN. Use of commercial record linkage software and vital statistics to identify patient deaths. J Am Med Inform Assoc. 1997;4:233-7.

23. Blackstone EH, Naftel DC, Turner ME Jr. The decomposition of time-varying hazard into phases, each incorporating a separate stream of concomitant information. J Am Stat Assoc. 1986;81:615-24.

24. Svensson LG, Dewey T, Kapadia S, Roselli EE, Stewart A, Williams M, et al. United States feasibility study of transcatheter insertion of a stented aortic valve by the left ventricular apex. Ann Thorac Surg. 2008;86:46-54; discussion 54-5.

25. Osswald BR, Gegouskov V, Badowski-Zyla D, Tochtermann U, Thomas G, Hagl S, et al. Overestimation of aortic valve replacement risk by EuroSCORE: implications for percutaneous valve replacement. Eur Heart J. 2009;30:74-80.

26. Svensson LG. Evolution and results of aortic valve surgery, and a "disruptive" technology. Cleve Clin J Med. 2008;75:802-4.

APPENDIX 1. Variables used in analyses

\section{Preoperative \\ Demographic \\ Symptoms \\ Ventricular dysfunction \\ Aortic valve pathology \\ Aortic valve disease \\ Other valve pathology \\ Coronary anatomy}

Other cardiac comorbidity

Noncardiac comorbidity

Experience

Intraoperative

Aortic valve procedure

Other procedure

Surgeon
Age $(\mathrm{y}),{ }^{*}$ gender,* race, ${ }^{*}$ weight $(\mathrm{kg})$, height $(\mathrm{cm})$, body surface area $\left(\mathrm{m}^{2}\right)$, body mass index $\left(\mathrm{kg} \cdot \mathrm{m}^{-2}\right)^{*}$ NYHA functional class (I-IV)*

Previous myocardial infarction,* degree of left ventricular dysfunction*

Aortic valve regurgitation,* aortic valve stenosis*

Rheumatic,* degenerative,* congenital*

Tricuspid valve regurgitation*

Left main trunk disease ( $\%$ stenosis), ${ }^{*}$ left anterior descending coronary artery system disease

(maximum \% stenosis), ${ }^{*}$ right coronary artery system disease (maximum $\%$ stenosis), ${ }^{*}$ left circumflex coronary artery system disease (maximum $\%$ stenosis)*

Atrial fibrillation,* complete heart block,* ventricular arrhythmia*

Hypertension, $*$ treated diabetes, ${ }^{*}$ peripheral arterial disease, ${ }^{*}$ stroke, ${ }^{*}$ carotid disease, ${ }^{*}$ popliteal disease, ${ }^{*}$ endocarditis, ${ }^{*}$ smoking, ${ }^{*}$ renal disease, ${ }^{*}$ creatinine $\left(\mathrm{mg} \cdot \mathrm{dL}{ }^{-1}\right),{ }^{*}$ blood urea nitrogen $\left(\mathrm{mg} \cdot \mathrm{dL}^{-1}\right),{ }^{*}$

bilirubin $\left(\mathrm{mg} \cdot \mathrm{dL}^{-1}\right),{ }^{*}$ hematocrit $(\%)^{*}$

Date of operation (years since January 1, 1995)*

Repair,* replacement, prosthesis manufacturer*

Tricuspid valve repair*

$\mathrm{A}, \mathrm{B}, * \mathrm{C}, \mathrm{D}, * \mathrm{E}, \mathrm{F},{ }^{*} \mathrm{G}, * \mathrm{H}, \mathrm{I}, \mathrm{J} *$

NYHA, New York Heart Association. *Variables included in propensity score. 


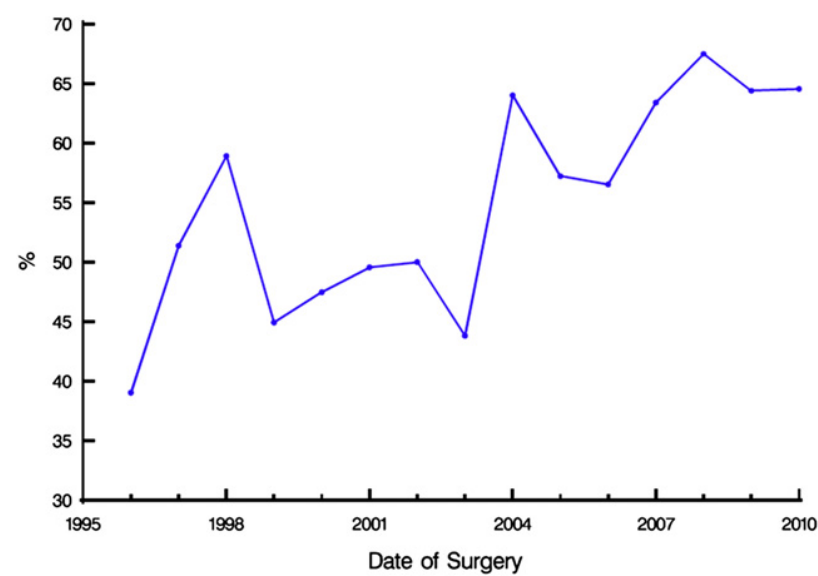

FIGURE E1. Percent of aortic valve surgery performed through a lessinvasive incision. This graph incorporates cases performed after the study period.

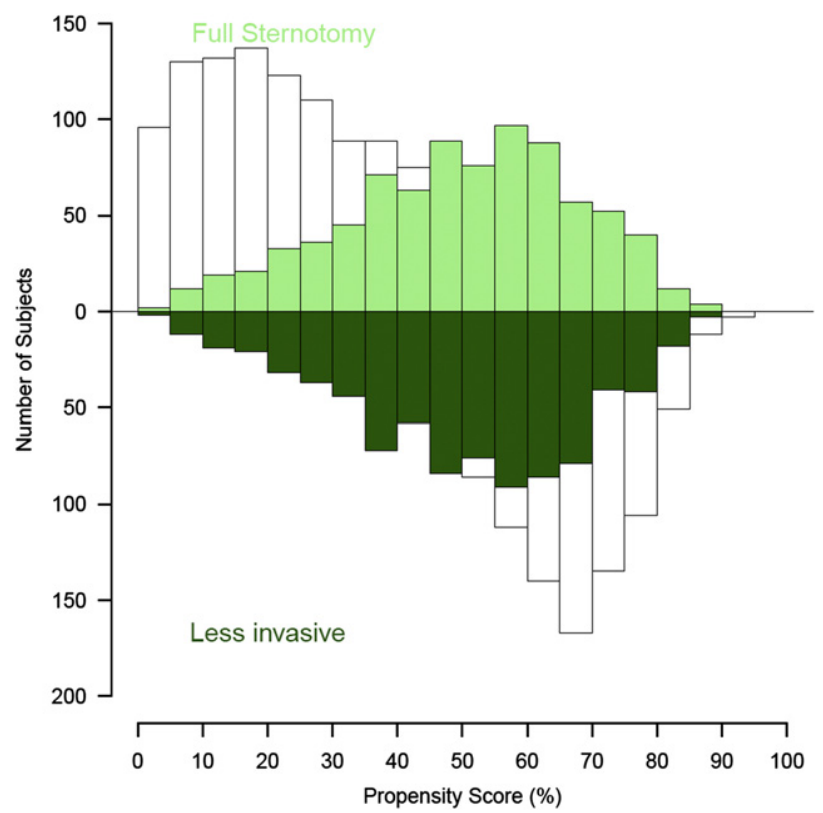

FIGURE E2. Mirrored histogram of distribution of propensity scores for full sternotomy (bars above zero line) and less invasive (bars below zero line) approaches. Darkened area represents matched patient pairs, showing that they cover the complete spectrum of cases.

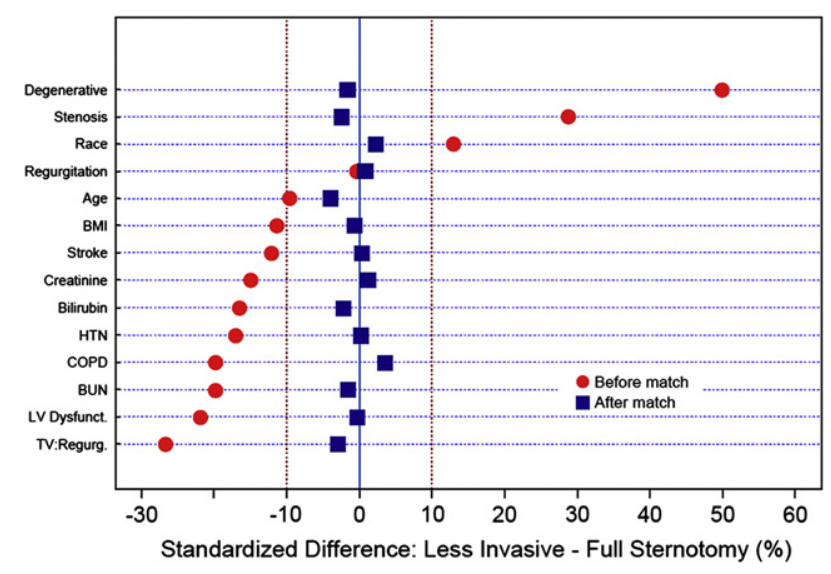

FIGURE E3. Covariable balance plot before and after propensity-score matching on selected covariables. Symbols depict percent standardized differences ${ }^{17}$ for covariables between patients in less invasive and full sternotomy groups. BMI, Body mass index; $B U N$, blood urea nitrogen; $C O P D$, chronic obstructive pulmonary disease; Dysfunct., dysfunction; HTN, hypertension; $L V$, left ventricular; Regurg., regurgitation; $T V$, tricuspid valve.

TABLE E1. Parsimonious model of factors associated with less invasive versus full sternotomy for aortic valve surgery*

\begin{tabular}{lccc}
\hline Factor & Coefficient \pm SD & $\boldsymbol{P}$ & Reliability $(\%) \dagger$ \\
\hline Higher likelihood of & & & \\
$\quad$ full sternotomy & & & \\
Heavier $\ddagger$ & $0.38 \pm 0.86$ & $<.0001$ & 78 \\
Severe LV dysfunction $\S$ & $0.043 \pm 0.012$ & .0004 & 85 \\
Severe TV regurgitation & $0.31 \pm 0.061$ & $<.0001$ & 60 \\
Higher BUN & $0.026 \pm 0.006$ & $<.0001$ & 74 \\
Surgeon D & $0.79 \pm 0.17$ & $<.0001$ & 99 \\
Surgeon G & $0.805 \pm 0.17$ & $<.0001$ & 99 \\
Higher likelihood of less & & & \\
$\quad$ invasive approach & & & \\
AV etiology & & & \\
$\quad$ Degenerative & $1.3 \pm 0.11$ & $<.0001$ & 100 \\
$\quad$ Rheumatic & $1.2 \pm 0.17$ & $<.0001$ & 100 \\
Surgeon B & $0.54 \pm 0.16$ & .0008 & 99 \\
More recent operation $\|$ & $0.51 \pm 0.059$ & $<.0001$ & 100 \\
\hline St
\end{tabular}

$S D$, Standard deviation; $L V$, left ventricular; $T V$, tricuspid valve; $B U N$, blood urea nitrogen; $A V$, aortic valve. *Obtained by logistic regression with variable selection by bagging. (Breiman L. Bagging predictors. Machine Learning. 1996;24:123-40.) $\dagger$ Frequency of occurrence in 1000 bootstrap models. $\ddagger(\text { Weight/80 })^{2}$, squared transformation. $\S\left(\right.$ LV dysfunction grade) ${ }^{2}$ squared transformation. ||Log(interval from 1/1/ 1995) to date of operation, logarithmic transformation. 
TABLE E2. Patient characteristics and operative details by surgical approach: Propensity-matched pairs

\begin{tabular}{|c|c|c|c|c|c|c|c|c|c|c|}
\hline \multirow[b]{3}{*}{ Variable } & \multicolumn{5}{|c|}{ Propensity matched } & \multicolumn{5}{|c|}{ Unmatched } \\
\hline & \multicolumn{2}{|c|}{$\begin{array}{l}\text { Less invasive } \\
\quad(\mathbf{n}=\mathbf{8 3 2})\end{array}$} & \multicolumn{2}{|c|}{$\begin{array}{l}\text { Full sternotomy } \\
\qquad(\mathbf{n}=\mathbf{8 3 2})\end{array}$} & \multirow[b]{2}{*}{$\boldsymbol{P}$} & \multicolumn{2}{|c|}{$\begin{array}{l}\text { Less invasive } \\
\quad(\mathbf{n}=\mathbf{3 6 1})\end{array}$} & \multicolumn{2}{|c|}{$\begin{array}{l}\text { Full sternotomy } \\
\quad(\mathbf{n}=664)\end{array}$} & \multirow[b]{2}{*}{$P$} \\
\hline & No. & $\%$ & No. & $\%$ & & No. & $\%$ & No. & $\%$ & \\
\hline \multicolumn{11}{|l|}{ Demography } \\
\hline Women & 298 & 36 & 293 & 36 & .8 & 92 & 25 & 239 & 36 & .0006 \\
\hline Age $(y)$, mean $\pm S D$ & \multicolumn{2}{|c|}{$60 \pm 16$} & \multicolumn{2}{|c|}{$61 \pm 17$} & .5 & \multicolumn{2}{|c|}{$56 \pm 16$} & \multicolumn{2}{|c|}{$60 \pm 16$} & $<.0001$ \\
\hline $\begin{array}{l}\mathrm{BMI}\left(\mathrm{kg} \cdot \mathrm{m}^{-2}\right) \\
\quad \text { mean } \pm \mathrm{SD}\end{array}$ & \multicolumn{2}{|c|}{$28 \pm 6.1$} & \multicolumn{2}{|c|}{$28 \pm 5.5$} & .6 & \multicolumn{2}{|c|}{$27 \pm 4.1$} & \multicolumn{2}{|c|}{$29 \pm 6.2$} & $<.0001$ \\
\hline NYHA functional class & & & & & $>.9$ & & & & & $<.0001$ \\
\hline I & 194 & 23 & 190 & 23 & & 88 & 24 & 170 & 26 & \\
\hline II & 482 & 58 & 486 & 58 & & 237 & 66 & 289 & 44 & \\
\hline III & 127 & 15 & 126 & 15 & & 27 & 7.5 & 142 & 21 & \\
\hline IV & 29 & 3.5 & 30 & 3.6 & & 9 & 2.5 & 63 & 9.5 & \\
\hline \multicolumn{11}{|l|}{ Indication for operation } \\
\hline Degenerative & 615 & 74 & 618 & 74 & .9 & 312 & 86 & 200 & 30 & $<.0001$ \\
\hline Rheumatic & 73 & 8.8 & 71 & 8.5 & .9 & 32 & 8.9 & 41 & 6.2 & .1 \\
\hline Congenital & 52 & 6.3 & 48 & 5.8 & .7 & 17 & 4.7 & 67 & 10 & .003 \\
\hline Other & 92 & 11 & 95 & 11 & .8 & 0 & 0 & 356 & 54 & $<.0001$ \\
\hline \multicolumn{11}{|l|}{ Cardiac comorbidity } \\
\hline LV dysfunction & $155 / 804^{*}$ & 19 & $144 / 794 *$ & 18 & .5 & $43 / 352 *$ & 12 & $183 / 581 *$ & 31 & $<.0001$ \\
\hline $\begin{array}{l}\text { Tricuspid regurgitation } \\
>\text { moderate }\end{array}$ & $14 / 762 *$ & 18 & $22 / 752 *$ & 29 & .2 & $0 / 351^{*}$ & 0 & $35 / 459 *$ & 7.4 & $<.0001$ \\
\hline Atrial fibrillation/flutter & 30 & 3.6 & 29 & 3.5 & .9 & 6 & 1.7 & 45 & 6.8 & .0003 \\
\hline \multicolumn{11}{|l|}{ Noncardiac comorbidity } \\
\hline Hypertension & $460 / 816^{*}$ & 56 & $452 / 816^{*}$ & 55 & .7 & $141 / 356^{*}$ & 40 & $417 / 643 *$ & 65 & $<.0001$ \\
\hline Treated diabetes & $60 / 814 *$ & 7.4 & $55 / 811 *$ & 6.8 & 6 & $8 / 356^{*}$ & 2.2 & $78 / 625^{*}$ & 12 & $<.0001$ \\
\hline COPD & $136 / 749^{*}$ & 18 & $124 / 740 *$ & 17 & .5 & $41 / 352 *$ & 12 & $158 / 445^{*}$ & 36 & $<.0001$ \\
\hline \multicolumn{11}{|l|}{ Procedure } \\
\hline Aortic valve repair & 126 & 15 & 118 & 14 & 6 & 68 & 19 & 126 & 19 & $>.9$ \\
\hline $\begin{array}{l}\text { Aortic valve replacement } \\
\text { Label size }(\mathrm{mm}) \dagger\end{array}$ & 706 & 85 & 714 & 86 & 6 & 293 & 81 & 538 & 81 & $>.9$ \\
\hline$\leq 19$ & 71 & 10 & 82 & 12 & & 26 & 8.9 & 49 & 9.5 & \\
\hline $20 / 21$ & 224 & 32 & 198 & 28 & & 90 & 31 & 133 & 26 & \\
\hline $22 / 23$ & 259 & 37 & 235 & 33 & & 107 & 37 & 164 & 32 & \\
\hline $24 / 25$ & 111 & 16 & 115 & 16 & & 59 & 20 & 113 & 22 & \\
\hline $26 / 27$ & 39 & 5.5 & 61 & 8.6 & & 10 & 3.4 & 44 & 8.5 & \\
\hline$\geq 28$ & 2 & 0.28 & 18 & 2.5 & & 1 & .34 & 14 & 2.7 & \\
\hline Tricuspid valve repair & 3 & 0.36 & 10 & 1.2 & .05 & 0 & 0 & 13 & 1.9 & .008 \\
\hline
\end{tabular}

$S D$, Standard deviation; $B M I$, body mass index; $N Y H A$, New York Heart Association; $L V$, left ventricular; $C O P D$, chronic obstructive pulmonary disease. *Number of patients with data available. †'In the full sternotomy group, 709 (of 714) propensity-matched and 517 (of 538) unmatched patients have label size data. 
TABLE E3. Timing and reasons for conversion from less invasive to full sternotomy approach

\begin{tabular}{|c|c|c|c|}
\hline Timing of conversion & Patient & General reason & Additional details \\
\hline \multicolumn{4}{|l|}{ Before clamping } \\
\hline & 1 & Poor exposure & Inadequate cardioplegia (misplaced retrograde catheter) \\
\hline & 2 & Poor exposure & Aorta calcified \\
\hline & 3 & Poor exposure & Heart low, adhesions \\
\hline & 4 & Poor exposure & Heart low \\
\hline & 5 & Poor exposure & Heart low \\
\hline & 6 & Poor exposure & Heart low \\
\hline & 7 & Poor exposure & Heart low \\
\hline & 8 & Poor exposure & Heart low, leftward \\
\hline & 9 & Poor exposure & Leftward heart \\
\hline & 10 & Poor exposure & Left ventricular hypertrophy \\
\hline & 11 & Poor exposure & Frozen right chest \\
\hline & 12 & Poor exposure & Radiation heart disease \\
\hline & 13 & Poor exposure & \\
\hline & 14 & Adhesions & \\
\hline & 15 & IVC injury during cannulation & Ascending aortic repair \\
\hline & 16 & Coronary sinus perforation & \\
\hline & 17 & Change in procedure plan & SAM and septal hypertrophy on ECHO, myectomy \\
\hline & 18 & Ascending aorta repair & \\
\hline \multicolumn{4}{|l|}{ During clamping } \\
\hline & 19 & Poor exposure & Anterior annulus calcification \\
\hline & 20 & Patent ductus & Intraoperative discovery of large patent ductus requiring repair \\
\hline & 21 & LM injury & Repair of LM injury during coronary button mobilization \\
\hline & 22 & Uncertain & Uncertain \\
\hline \multicolumn{4}{|l|}{ After clamping } \\
\hline & 23 & RV dysfunction & Planned for grafting, improved over time \\
\hline & 24 & Fibrillation & To allow paddles \\
\hline & 25 & Distention & VF unable to defibrillate, opened to place LV vent \\
\hline & 26 & Distention & VF opened for manual compression \\
\hline & 27 & Distention & $\mathrm{VF}$ and $\mathrm{AI}$ for adequate defibrillation \\
\hline & 28 & Right atrial bleeding & \\
\hline & 29 & Right atrial bleeding & \\
\hline & 30 & Coronary sinus perforation & \\
\hline & 31 & Coronary sinus perforation & \\
\hline & 32 & Bleeding from root & Case converted to root replacement, calcification \\
\hline & 33 & Cardiac arrest, tamponade & \\
\hline & 34 & Reopen in OR for arrest & \\
\hline
\end{tabular}

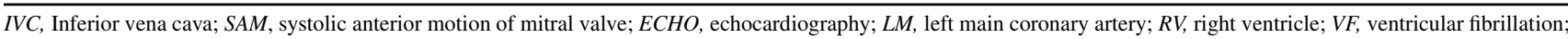
$L V$, left ventricle; $A I$, aortic insufficiency; $O R$, operating room. 